\title{
ÍNDICES DE RISCO SISTÊMICO PARA O SETOR BANCÁRIO
}

\author{
SYSTEMIC RISK INDICATORS FOR THE BANKING SECTOR
}

\author{
LUCIO RODRIGUES CAPELLETTO \\ Professor Doutor e Pesquisador Associado \\ do Programa Multinstitucional e Inter-regional de \\ Pós Gráduação em Ciênciaș Contábeis da UnB, UFPB e UFRN. \\ E-mail: capelletto@bcb.gov.br
}

\author{
LUIZ JOÃO CORRAR \\ Professor Doutor do Departamento de Contabilidade e Atuária \\ da Faculdade de Economia, Administração e Contabilidade \\ da Universidade de São Paulo - Campus Capital \\ E-mail: ljcorrar@usp.br
}

\section{RESUMO}

Os vultosos custos econômicos e sociais resultantes de crises financeiras têm conduzido os esforços de organismos internacionais e autoridades de supervisão para pesquisas sobre o risco sistêmico. O objetivo tem sido buscar características comuns que possam prever a proximidade das crises. Na mesma linha, este estudo visou desenvolver índices de risco sistêmico (IRS), formados por variáveis contábeis e de riscos, capazes de mensurar o nível de risco sistêmico no setor bancário. A regressão logística revelou a existência de indicadores com significância estatística na segregação dos sistemas bancários pelo nível de risco, especialmente aqueles relacionados com: a qualidade dos créditos, os resultados e a taxa de juros. Os indicadores identificados como mais relevantes são: a volatilidade da inadimplência, da rentabilidade e da taxa de juros, e a média da rentabilidade e do risco de crédito. Além disso, a comparação da evolução dos indicadores com as crises ocorridas demonstrou a eficácia dos IRS na mensuração do risco nas crises bancárias sistêmicas.

Palavras-chave: Crise bancária. Crise financeira. Risco. Contabilidade. Indicadores.

\section{ABSTRACT}

The significant economic and social costs caused by financial crises have conducted the efforts of international institutions and supervisory authorities towards research about systemic risk. The main goal has been to identify common characteristics able to foresee the proximity of crises. Likewise, this study aimed to develop systemic risk indicators (IRS), comprising accounting and economic variables, able to measure the systemic risk level of the banking sector. The indicators were submitted to logistic regression analysis and the results revealed indicators able to discriminate banking systems according to the risk level with statistical significance. The most relevant indicators are related to the volatility of non-performing loans, profitability and interest rate, as well as mean profitability and credit risk. In addition, the comparison between the indicators' evolution and the crises that have occurred demonstrated the IRS' efficacy for risk measurement in systemic banking crises.

Keywords: Banking crises. Financial crises. Risk. Accounting. Indicators. 


\section{INTRODUÇÃO}

A mensuração de riscos no sistema financeiro é marcada com a publicação do Acordo de Capital da Basiléia (BCBS, 1988), pelo BCBS (Comitê de Basiléia sobre Supervisão Bancária), que estabeleceu a aferição do valor em risco pela relação entre os ativos e o patrimônio líquido, modificando o conceito vigente que considerava o endividamento calculado pela razão entre o passivo e o patrimônio líquido.

A mudança conduziu os estudos para os riscos inerentes às atividades cotidianas das instituições financeiras, destacando-se aqueles relacionados aos riscos de crédito, taxa de juros, câmbio, liquidez e, mais recentemente, ao risco operacional. O desafio passou a ser a obtenção de melhores formas de controle e de mensuração de riscos, com vistas à assunção de posições e à geração de lucros, sem incorrer na possibilidade de insolvência.

Ao mesmo tempo, o crescente número de operações financeiras e a maior interdependência dos mercados fizeram com que o sistema financeiro internacional assumisse a função de principal propagador de riscos. Independentemente do estágio de desenvolvimento e da solidez dos fundamentos econômicos, todos os países participantes do sistema se tornaram suscetíveis às fragilidades verificadas em outros países.

As crises financeiras observadas em países da América Latina, do Sudeste Asiático, e na Rússia, entre os anos de 1993 e 1998, ratificam esse entendimento, pois foram originadas por fraquezas nos setores financeiro e empresarial, combinadas com vulnerabilidades econômicas (CAPRIO et al., 1998, p. 346).

Em termos de valores, Honohan e Klingebiel (2002, p. 16) mostraram que o custo fiscal médio de crises no sistema financeiro, extraído de uma amostra de quarenta (40) países emergentes e industrializados com experiências de crises no período entre 1975 e 2000, aproxima-se de 13\% do PIB (Produto Interno Bruto).

Sensíveis ao problema e motivados pelas crises financeiras ocorridas em 133 países membros do FMI (Fundo Monetário Internacional), entre 1980 e 1996 (LINDGREN; GARCIA; SAAL, 1996, p. 20), organismos internacionais, como o BIS (Bank for International Settlements) têm envidado esforços para controlar os riscos nos sistemas financeiros e coibir exposições acima de padrões que impliquem em perigo à continuidade das instituições e dos mercados.

Considerando que a associação de diferentes tipos de riscos possa configurar situações não observadas na análise do risco isoladamente, estudos com enfoque integrado tornamse importantes. O acompanhamento dos riscos de modo conjunto permite a identificação do momento em que patamares perigosos para a estabilidade do sistema são atingidos.

Nesse sentido, o objetivo do estudo é verificar se os indicadores formados por variáveis contábeis e de riscos são capazes de mensurar o nível de risco sistêmico no setor bancário, bem como demonstrar a eficácia de sua utilização em alguns países da amostra.

\section{RISCOS}

\subsection{Conceito Geral}

O risco é uma variável determinante da evolução humana, pois a sua ausência implica a certeza de resultados e a restrição à construção de conhecimentos. Não obstante o antigo conceito, a concepção atual de risco tem origem nos números que permitem quantificar o valor incerto, antes abstrato, produzido por determinada ação.

A avaliação da incerteza representou o domínio do risco e definiu a fronteira entre os tempos moderno e passado, pois, segundo Bernstein (1997, p. 1), "[...] a noção de que o futuro é mais do que um capricho dos deuses e de que homens e mulheres não são passíveis ante a natureza".

Em finanças, o risco é a probabilidade de não obter o retorno esperado no investimento realizado. O risco é definido como a própria variância do retorno. Quanto maior a amplitude desse desvio, maior será o resultado exigido para compensar o risco assumido.

Basicamente, dois fatores causam o desvio do retorno. Um referente às características intrínsecas da operação ou da contraparte, como a garantia prestada ou a capacidade de pagamento do devedor, chamado de risco idiossincrático, não-sistemático ou diversificável. E outro, não-controlável, inerente ao ambiente ou ao sistema, conhecido como risco sistemático ou não-diversificável (MARTINS; ASSAF NETO, 1986, p. 467).

Nesse sentido, Ross, Westerfield e Jaffe (1995, p. 233) definem: "Um risco sistemático é qualquer risco que afeta um grande número de ativos, e cada um deles com maior ou menor intensidade.", e "Um risco não-sistemático é um risco que afeta especificamente um único ativo ou um pequeno grupo de ativos." $\mathrm{A}$ imprecisão na quantidade e o acréscimo na gradação da intensidade ampliam a abrangência e a caracterização do risco sistemático.

Ao relacionar o risco sistemático com aspectos sociais, Securato (1996, p. 42) apresenta o risco conjuntural (ou sistemático) como "o risco que os sistemas econômico, político e social, vistos de forma ampla, impõem ao ativo". Esse enfoque ressalta que o risco está relacionado às possibilidades de variação na conjuntura, que, por sua vez, é diretamente afetada pelo nível de credibilidade no sistema como um todo.

Sobre o assunto ainda, não é possível omitir a contribuição de Markowitz para a teoria de finanças (MARKOWITZ, 1952). Ao introduzir a noção de risco e de diversificação na formação de carteira de ações, ele revolucionou a gestão de riscos. A inserção do conceito de diversificação 
na estratégia de investimentos proporcionou a obtenção da carteira "eficiente", diminuindo os efeitos dos riscos idiossincráticos de cada um dos ativos.

A genialidade do modelo foi provar que a volatilidade no retorno de uma carteira pode ser minimizada pela aplicação em ativos que sejam negativamente correlacionados entre si.

No mercado internacional, os países representam oportunidades de investimentos com riscos e retornos distintos. As diferenças residem na percepção da qualidade dos fundamentos econômicos e da solidez do sistema financeiro de cada país. Diante disso, o investidor internacional tende a diversificar a sua carteira, escolhendo os países localizados na linha da carteira eficiente, que agregam ao conjunto um retorno melhor e menor risco.

Dado que o nível de risco sistêmico do país corresponde ao risco idiossincrático no cenário internacional, o conhecimento das causas e do nível permite a adoção de estratégias que visem à redução do risco e melhorem a atratividade do país para os investidores.

\subsection{Riscos inerentes ao Sistema Financeiro}

O sistema financeiro tem especificidades operacionais que o diferenciam dos demais setores. A função de intermediar recursos entre os agentes superavitários, denominados investidores, e os agentes deficitários, tomadores de recursos, coloca os intermediadores financeiros no centro do fluxo econômico.

As atividades de transformação dos prazos e da magnitude dos objetos transacionados são permeadas por riscos que exigem controles adequados e capacitação gerencial. Somente com o adequado gerenciamento de riscos, as instituições financeiras são capazes de oferecer menores custos e maior eficiência no cumprimento de suas atividades.

Pelo lado dos usuários do sistema financeiro, Securato (1996, p. 86) salienta a importância de classificar os bancos pelo grau de risco, à medida que cumpre a função de "mostrar claramente ao investidor o direito a um prêmio por estar correndo este risco", e "fazer com que os bancos procurem ser o mais aberto possível para com seu público, com a finalidade de mostrar o baixo nível de exposição ao risco".

Com vistas à melhor compreensão dos principais riscos encontrados nas operações realizadas no sistema financeiro, os riscos de crédito, de mercado e de liquidez são a seguir detalhados.

\subsubsection{Risco de crédito}

O risco de crédito é a probabilidade de o tomador dos recursos não pagar ou honrar as obrigações assumidas, tanto no que tange ao principal quanto ao serviço da dívida.

Segundo Bessis (1998, p. 81), "Risco de crédito é definido pela perda no evento de não pagamento do devedor, ou no evento de deterioração da qualidade do crédito do devedor." A definição acrescenta a ocorrência de elevação do risco não somente pelo inadimplemento, mas também pela redução da capacidade de pagamento do devedor.

Para mensurar, adequadamente, o risco de crédito, duas dimensões devem ser observadas. Uma de ordem quantitativa, relativa ao montante de crédito concedido, e outra qualitativa, que abrange aspectos como a situação econômico-financeira do tomador do crédito, o histórico de inadimplemento, a aplicação dada aos recursos, a moeda, o indexador e o prazo da operação, a atividade econômica predominante e as garantias (BESSIS, 1998, p. 6).

Securato e Famá (1997), ao proporem um modelo de decisão para a concessão de crédito, transformam as variáveis qualitativas em quantitativas, considerando a probabilidade de ocorrência de determinados eventos na data do pagamento: a taxa de juros e o risco que o banco está disposto a correr. Por meio desse modelo, os autores buscam adequar as taxas de remuneração cobradas na concessão das operações de crédito aos riscos assumidos.

\subsubsection{Risco de mercado}

O BCBS (1996, p. 1) define o risco de mercado como a possibilidade de perda em posições, dentro e fora do balanço, provocada por movimentos nos valores de mercado originados de alterações nas taxas de juros e de câmbio, e nos preços de ações e de commodities.

Particularmente ao risco de taxa de juros, o BCBS (2004, p. 5) considera como "[...] a exposição da situação financeira do banco a movimentos adversos na taxa de juros." Essa exposição ao risco de taxa de juros é calculada sobre todas as posições ativas, passivas e em derivativos, remuneradas pelas taxas de juros prefixadas ou pós-fixadas, ou cujo valor sofra alterações quando há variação na taxa de juros.

Analogamente ao risco de taxa de juros, o risco de câmbio é a probabilidade de perda em virtude de variação adversa na taxa de câmbio. Ao assumir posições líquidas ativas ou passivas, também chamadas de compradas ou vendidas, respectivamente, a instituição fica exposta à variação cambial. De acordo com Greuning e Bratanovic (1999, p. 211), o risco de câmbio é "[...] um risco de volatilidade devido ao descasamento das posições, e pode causar perdas resultantes de movimentos adversos durante o período em que a posição estava aberta em moeda estrangeira, no balanço ou fora dele, no mercado à vista ou futuro."

A principal diferença entre o risco de taxa de juros e o de câmbio está no caráter exógeno dessa última. Enquanto a taxa de juros é administrada internamente e consiste em uma decisão até certo ponto autônoma da autoridade monetária, a taxa de câmbio é determinada por fatores externos, não-controláveis pelos países.

O risco de preços, por sua vez, é a probabilidade de perda associada à alteração nos preços de mercado de ativos, passivos e itens extra-patrimoniais. A diferença em relação aos riscos de taxa de juros e de câmbio está na inexistência de um indexador de referência explícito para remunerar o item objeto. O valor é dado pelo preço de mercado, sem vinculações. 
Os itens expostos ao risco de preços, no sistema financeiro, estão restritos aos valores mobiliários, classificados como títulos de renda variável, em face da dependência do retorno ao desempenho do emissor, e commodities.

\subsubsection{Risco de liquidez}

O risco de liquidez é causado pelos descasamentos de prazo, indexador, moeda e valor entre os pagamentos e os recebimentos. Conforme o BCBS (2000, p. 1), “[...] a importância da liquidez transcende o banco individualmente, desde que a escassez de liquidez em uma simples organização possa ter repercussões sistêmicas. Assim, o gerenciamento de liquidez está entre as atividades mais importantes conduzidas pelos bancos."

A falta de liquidez obriga a rápida realização de ativos e provoca a queda nos preços, desvalorizando ativos iguais ou semelhantes detidos por outras instituições. A constatação desse fato pelos depositantes é suficiente para provocar saques inadvertidos e gerar a "corrida bancária", que constitui importante preocupação das autoridades monetárias.

\subsubsection{Risco sistêmico}

As definições de risco sistêmico no setor financeiro, encontradas na literatura, são variadas e estão relacionadas aos objetivos das pesquisas. Algumas têm como essência a ocorrência de um choque capaz de produzir efeitos adversos na maior parte do sistema ou da economia.

Sob esse enfoque, Bartholomew e Whalen (1995, p. 4) apresentam o risco sistêmico como: "[...] um evento com efeitos em todo o sistema econômico e financeiro, e não apenas em poucas instituições." Na definição, os participantes não precisam estar conectados, pois o choque é suficientemente abrangente e forte para atingir todos indistintamente.

Outras definições são baseadas no efeito da contaminação dos problemas de um agente para outros, chamado de "efeito contágio". O BIS (1994, p. 177) define como: "O risco que o não cumprimento das obrigações contratuais por um participante pode causar ao cumprimento das obrigações de outros pode gerar uma reação em cadeia de dificuldades financeiras maiores." Nesse caso, a premissa é a conectividade entre os participantes.

Apesar das várias definições, Freixas, Parigi e Rochet (1999, p. 2) mencionam que a teoria ainda não conseguiu consolidar uma estrutura conceitual apropriada sobre risco sistêmico. De qualquer forma, todas mencionam a presença de eventos turbulentos suficientemente fortes $e$ a propagação pelo "efeito contágio" como causa da instabilidade generalizada.

Para o estudo, o risco sistêmico é o grau de incerteza existente no sistema resultante de variações no nível de risco do crédito, da taxa de juros e do câmbio. A mensuração é feita pelo impacto da variação do risco sobre o patrimônio líquido do sistema. Quanto maior a perda nãoesperada potencial, maior é o risco sistêmico. A crise é configurada no estresse do risco sistêmico, quando todos perdem a credibilidade na continuidade do sistema.

Dessa forma, a observação dos efeitos dos choques sobre as variáveis de natureza econômica, como taxa de juros, taxa de câmbio e reservas internacionais, e de natureza contábil, como créditos vencidos, ativos líquidos, depósitos à vista e patrimônio líquido permitem a mensuração do nível de risco sistêmico e da proximidade das crises.

\subsection{Fundamentação do Patrimônio líquido como referência à cobertura de riscos}

Formuladas as definições básicas sobre risco sistêmico e crise bancária, depreende-se que a característica básica para existência e funcionamento de um sistema financeiro é a confiança. Os agentes superavitários e deficitários somente procuram o intermediário financeiro porque acreditam que seus interesses são seguramente atendidos.

A garantia, em termos contábeis, está expressa na diferença positiva entre os ativos e os passivos da instituição. A superioridade dos valores ativos indica que a instituição tem capacidade de honrar todas as obrigações e ainda sobram recursos para os proprietários. Nessa situação, diz-se que a instituição tem patrimônio líquido positivo e está solvente.

A preocupação com o valor do patrimônio líquido ganha relevância no âmbito do sistema financeiro, visto que a maior alavancagem proporciona mais retorno, a exposição a riscos é constante, as instituições operam interligadas e a confiança é crucial para o funcionamento.

A falta de capitalização implica em vulnerabilidade ante o inesperado, tornando a instituição ou o sistema frágil. Mesmo problemas na qualidade dos ativos ou a perda de depósitos podem ser suportados quando há patrimônio líquido em nível adequado.

Nessa linha, o Acordo de Capital e seus respectivos amendments foram motivados pela percepção de que a intensa concorrência internacional estava induzindo alguns bancos a operar com baixos níveis de capital, em proporção ao volume de ativos, tornando-se mais competitivos na busca da ampliação de suas parcelas de mercado.

Para limitar as exposições ao risco, as instituições foram compelidas a manter um nível mínimo de capital compatível com o grau de risco de suas operações ativas, passivas e fora do balanço, o qual ficou conhecido no Brasil como Limite de Basiléia.

\subsection{Avaliação de Riscos}

Os modelos e as técnicas de avaliação podem ser agrupados de acordo com o tipo de risco mensurado. Basicamente, são divididos entre os destinados a estimar o valor em risco de mercado e aqueles voltados para aferir o valor em risco de crédito.

\subsubsection{Avaliação do risco de mercado}

As técnicas de avaliação do risco de mercado estão em constante evolução. Atualmente, o instrumento mais utilizado é a mensuração do valor em risco (VaR). O pró- 
prio BCBS (1996) recomenda o uso do VaR pelos Bancos, tanto o modelo interno como a abordagem padronizada, para alocação de capital destinado à cobertura do risco de mercado.

A simplicidade de compreensão e a capacidade em responder o quanto pode ser perdido, considerando certa probabilidade e período, disseminaram o uso do VaR. De acordo com Jorion (2003, p. 95), "[...] a maior vantagem do VaR consiste em resumir, num único número de fácil compreensão, a exposição total ao risco de mercado de uma instituição."

Crouhy, Galai e Mark (2004, p. 168) definem o VaR como "[...] a pior perda que poderia ser esperada em decorrência de se deter um título ou uma carteira por um dado período de tempo, dado um nível especificado de probabilidade." Para fins de cálculo, os autores apresentam três abordagens diferentes, as quais têm em comum a necessidade do prazo, do nível de significância, e das taxas e valores dos ativos e passivos existentes na carteira.

Como no estudo os dados utilizados são contábeis, sem a existência de longas séries históricas e não há presunção sobre a distribuição da volatilidade, o cálculo do VaR é realizado pela abordagem analítica de variância-covariância, dada pela seguinte fórmula:

$$
\operatorname{VaR}(H ; c)=V M *\left(\mu-R^{\prime}\right)
$$

em que: $H$ é o horizonte de tempo; c é o nível de confiança; VM é o valor de mercado da posição; $\mu$ é o retorno médio esperado e R' é a pior perda possível ao nível de confiança estabelecido. O pior retorno é calculado pela fórmula:

$$
R^{\prime}=\mu+\alpha^{*} \sigma
$$

em que: $\alpha$ é o valor correspondente ao nível de confiança, obtido na tabela de distribuição normal padronizada unilateral' ${ }^{1}$, e $\sigma$ é o desvio-padrão do retorno. Desse modo, para obter o VaR, basta substituir o R' na fórmula (1):

$$
\operatorname{VaR}(H ; c)=-\alpha^{*} \sigma^{*} V M
$$

\subsubsection{Avaliação do risco de crédito}

Igualmente, os estudos sobre risco de crédito avançam a fronteira do conhecimento. O desafio é tratar o risco de crédito de forma agregada, como é feito para o risco de mercado.

Caouette, Altman e Narayanan (1999, p. 122), ao descrevê-los funcionalmente, fazem a separação de acordo com o segmento-alvo, como o modelo de risco de crédito corporativo, baseado em preço de ações, o modelo de crédito ao consumidor, e o modelo de crédito para pequenas empresas, crédito imobiliário e instituições financeiras.
De outra forma, Crouhy, Galai e Mark (2004, p. 382) distinguem os modelos de avaliação do risco de crédito pelas premissas metodológicas do desenvolvimento. Para os autores, os principais modelos são: o KMV (KEALHOFER; BONH, 2001), o CreditMetrics (MORGAN, 1997), o CreditRisk + (CREDIT SUISSE FIRST BOSTON, 1997) e o CreditPortfolio View (WILSON, 1997a,b).

Apesar das diferenças, Caouette, Altman e Narayanan (1999, p. 221, 295) consideram que o "ingrediente-chave" do risco de crédito é o risco de inadimplência e que o cálculo do valor em risco para um único ativo depende apenas da volatilidade histórica do ativo.

Ratificando essa proposição, Crouhy, Galai e Mark (2004, p. 284) resumem "[...] o VaR de crédito de uma carteira é então obtido de forma semelhante ao de risco de mercado. É apenas a distância da média ao percentil da distribuição futura, no nível de confiança desejado."

Pelo exposto, é possível calcular o VaR para risco de crédito pela seguinte fórmula:

$$
\operatorname{VaR}(H ; c)=-\alpha^{*} \sigma_{T I}^{*} \operatorname{VExpCré}
$$

em que: $H$ é o horizonte de tempo; c é o nível de confiança; $\alpha$ é o valor correspondente ao nível de confiança, definido na tabela de distribuição normal padronizada unilateral; $\sigma_{\text {тा }}$ é o desvio-padrão da taxa de inadimplência e VExpCré é o valor exposto ao risco de crédito.

\subsection{Variáveis econômicas e contábeis para avaliar riscos}

As variáveis econômicas contêm informações agregadas da economia de países e são utilizadas para avaliar diversos aspectos como crescimento, produção, investimentos, endividamento, capacidade de pagamento, taxas de juros e de câmbio, saldos em reservas internacionais e em conta corrente, exportações e importações, poupança e crédito, inflação, enfim, tudo que serve de parâmetro à análise econômica de um país (IMF, 1996).

Apesar de serem interligados, os estudos sobre crises financeiras mostram que as variáveis econômicas representativas do PIB, da taxa de juros, da taxa de câmbio, das reservas internacionais e do conceito econômico do M2 são mais comumente encontradas no processo de identificação de crises (KAMINSKY; LIZONDO; REINHART, 1998).

Diferentemente, as variáveis contábeis são usadas para avaliar a situação econômico-financeira individual de instituições e sistemas financeiros. De acordo com o IMF (2001, p. 11), a metodologia mais utilizada na avaliação de instituições financeiras, conhecida como CAMELS², contempla informações relativas à adequação do capital, qualidade dos ativos, capacidade gerencial, resultados, liquidez e sensibilidade ao risco.

\footnotetext{
1 A tabela de distribuição normal padronizada está disponível em Downing e Clark (1998, p. 448).

2 Acrônimo de Capital, Assets, Management, Earnings, Liquidity e Sensibility, que expressa a metodologia de avaliação de instituições financeiras desenvolvida pelos supervisores bancários norte-americanos.
} 


\section{METODOLOGIA DA PESQUISA}

O estudo procura verificar a associação entre variáveis e indicadores econômico-contábeis e o nível de risco sistêmico, de um lado, e a ocorrência de crises no setor bancário, do outro, podendo ser classificado como empíricoanalítico (MARTINS, 2002, p. 34).

A utilização de testes estatísticos sobre os dados de países onde aconteceram crises bancárias sistêmicas pretende identificar as características comuns que as antecederam e possibilitar a construção de equações capazes de aferir o nível de risco sistêmico.

\subsection{Composição da amostra e identificação das crises}

A composição da amostra dependeu da existência de informações contábeis e econômicas, especialmente de países onde ocorreram crises financeiras significativas após 1990. Os trinta países selecionados estão divididos em dois grupos:

a) treze países com quinze observações de crise: Argentina, crises em mar/95 e dez/0I; Brasil, crises em dez/95 e jan/99; Equador, crise em mar/99; México, crise em dez/94; Uruguai, crise em mar/02; Venezuela, crise em dez/93; Coréia do Sul, crise em dez/97; Indonésia, crise em dez/97; Tailândia, crise em set/97; Finlândia, crise em set/92; Croácia, crise em dez/98; Rússia, crise em set/98 e Turquia, crise em mar/0 I.

b) dezessete países sem experiências de crise, pertencentes a OECD (Organization for Economic Cooperation and Development): Alemanha, Austrália, Áustria, Canadá, Dinamarca, Espanha, Estados Unidos, Finlândia, França, Holanda, Islândia, Itália, Nova Zelândia, Noruega, Portugal, Reino Unido e Suécia.

As experiências de crises bancárias nos países da amostra estão documentadas em Lindgren, Garcia e Saal (1996), Goldstein, Kaminsky e Reinhart (2000) e IMF (1998). As datas de início das crises, que servem de parâmetros à coleta e análise dos dados, foram extraídas de Caprio e Klingebiel (2003) e Demirgüç-Kunt e Detragiache (2005).

\subsection{Seleção de indicadores}

Os indicadores selecionados buscam prover informações sobre a situação econômica e financeira da posição agregada das instituições financeiras bancárias, bem como aferir a influência do ambiente econômico.

Dada a inexistência de um conjunto universalmente aceito para avaliar instituições e sistemas indiscriminadamente, abrangendo todas as variáveis existentes, a escolha foi discricionária e recaiu sobre aqueles usados na estrutura CAMELS.
As rubricas contábeis utilizadas nos indicadores contêm informações sobre o patrimônio líquido, o ativo total, os ativos líquidos, os créditos normais e vencidos, o total de depósitos e a exposição líquida em moeda estrangeira.

Mesmo com o foco no sistema financeiro, a elaboração dos indicadores contempla conceitos existentes em indicadores tradicionalmente utilizados na análise de demonstrações financeiras. De forma geral, os indicadores servem para analisar a estrutura, a liquidez e a rentabilidade de empresas comerciais e industriais, conforme especificam Matarazzo (2003) e Assaf Neto (2000) ${ }^{3}$.

Além disso, empregando o conceito de risco, alguns indicadores contábeis agregam a volatilidade do período no cálculo. A intenção é mensurar o impacto de perdas nãoesperadas sobre as variáveis que devem suportá-las.

Igualmente, para aferir a influência do ambiente econômico, foram construídos indicadores com a utilização de variáveis econômicas associadas aos riscos de crédito, de taxa de juros e de câmbio existentes nas variáveis contábeis.

Os indicadores econômico-contábeis (de risco) foram desenvolvidos sobre o conceito do VaR (JORION, 2003, p. 96) e da função do patrimônio líquido na cobertura de riscos (BCBS, 1988), expressos nos seguintes fatores necessários à existência e à quantificação dos riscos:

a) a volatilidade da variável econômica ou contábil que evidencia o risco específico.

b) a exposição ao risco específico, demonstrado pela Contabilidade.

c) o nível de capitalização, expresso pelo saldo do patrimônio líquido.

\subsubsection{Indicadores contábeis}

Os indicadores formados pelas variáveis contábeis são os seguintes:

a) indicador ativo total sobre patrimônio líquido (ATPL). Exibe o grau de alavancagem, que exprime a participação dos recursos de terceiros em relação aos recursos próprios utilizada para realizar as aplicações em operações ativas. Quanto maior o valor, maior o risco.

b) indicador de participação dos ativos líquidos sobre o total de depósitos (ALDT). Informa a liquidez existente. Quanto maior o valor, menor o risco.

c) indicador da taxa de inadimplência (CAOC), calculado pela divisão das operações de crédito vencidas sobre as operações de crédito. A deterioração na qualidade do crédito significa problemas no sistema bancário. Assim, quanto maior o valor, maior o risco.

d) indicador da posição líquida em moeda estrangeira sobre o patrimônio líquido (NOPPL). A posição líquida em moeda estrangeira é obtida pela diferença 
entre as posições ativas e passivas em moeda estrangeira. Quanto maior o valor, maior o risco.

e) indicador de rentabilidade do patrimônio líquido (ROE). A relação do resultado com o PL exprime quanto o sistema bancário obtém de retorno sobre os recursos próprios investidos. A importância da informação está no fato de os resultados serem o principal elemento de sustentação do capital. Quanto maior o valor, menor o risco.

\subsubsection{Indicadores de risco}

Todos os indicadores compostos pelas variáveis contábeis e econômicas para aferir os riscos, descritos a seguir, têm como parâmetros de cálculo $H$ igual a quatro trimestres, relativo ao horizonte de tempo; $c$ igual a $99 \%$, definido como intervalo de confiança e $-\alpha$ igual a 2,33 , correspondente ao intervalo de confiança unilateral encontrado na tabela de distribuição normal padronizada.

Indicador de mensuração do impacto da variação da taxa de câmbio no patrimônio líquido (IRFX), denominado índice de risco de câmbio e calculado pela fórmula:

$$
\operatorname{IRFX}(H ; c)=\frac{-\alpha * \sigma_{F X T J} *(V \operatorname{Exp} F X)}{P L}
$$

em que: $\sigma F X T$ é o desvio-padrão conjunto das taxas de câmbio e de juros; VExpFX é o valor contábil líquido exposto à variação cambial, obtido pela diferença entre ativos e passivos referenciados em moeda estrangeira e PL é o patrimônio líquido, na data da demonstração.

O objetivo é mostrar a capacidade do PL em suportar variações adversas na taxa de câmbio. $O$ indicador inferior a um $($ IRFX $<1)$ significa que o PL é suficiente para absorver a variação máxima possível na taxa de câmbio, para o intervalo de confiança estipulado. De forma contrária, o indicador superior a um (IRFX>1) denota insuficiência de PL.

Indicador de mensuração do impacto da variação da taxa de juros no patrimônio líquido (IRTJ), denominado índice de risco de taxa de juros e calculado pela fórmula:

$$
\operatorname{IRTJ}(H ; c)=\frac{-\alpha^{*} \sigma_{F X T J} *(V \operatorname{ExpTJ})}{P L}
$$

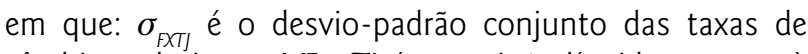
câmbio e de juros; VExpTJ é a posição líquida exposta à taxa de juros e PL é o patrimônio líquido, na data da demonstração. Similarmente ao IRFX, o indicador inferior a um $(I R T J<1)$ mostra que o PL é suficiente para absorver a variação máxima possível na taxa de juros, para o intervalo de confiança estipulado. O contrário evidencia que o PL é insuficiente.

Indicador de mensuração do impacto da variação da inadimplência no patrimônio líquido (IRCré), denominado índice de risco de crédito e calculado pela fórmula:

$$
\operatorname{IRCRE}(H ; c)=\frac{-\alpha^{*} \sigma_{T I}^{*}(V \operatorname{ExpCRE})}{P L}
$$

em que: $\sigma T$ T é o desvio-padrão da taxa de inadimplência; VExpCRE é o volume de créditos existente e PL é o patrimô- nio líquido. Com interpretação semelhante aos indicadores anteriores, o indicador mostra a capacidade do PL suportar variações na inadimplência. $O$ indicador inferior a um $(I R C R E<1)$ significa que o PL é suficiente para absorver a variação máxima possível na inadimplência, para o intervalo de confiança estipulado. $O$ indicador superior a um evidencia que o PL é insuficiente.

Indicador de mensuração do impacto da variação dos depósitos totais nos ativos líquidos (IRLIQ), denominado índice de risco de liquidez e calculado pela fórmula:

$$
\operatorname{IRLIQ}(H ; c)=\frac{-\alpha^{*} \sigma_{D T}}{A L}
$$

em que: $\sigma D T$ é o desvio-padrão dos depósitos totais e $A L$ é o montante de ativos líquidos. O objetivo é demonstrar se os ativos líquidos suportam as variações em depósitos causadas pelos saques. $\mathrm{O}$ indicador inferior a um $(I R L I Q<1)$ significa que os ativos líquidos são suficientes para honrar o saque máximo possível em depósitos, para o intervalo de confiança estipulado. O contrário evidencia que os ativos líquidos são insuficientes.

Indicador de mensuração da variação do ativo total em relação ao produto interno bruto (ATPIB), calculado pela fórmula:

$$
\operatorname{IRATPIB}(H ; c)=\frac{-\alpha^{*} \sigma_{A T}+A T}{P I B}
$$

em que: $\sigma A T$ é o desvio-padrão do ativo total; $A T$ é o montante de ativo total e PIB é o valor do produto interno bruto. $O$ indicador verifica se o valor do PIB é compatível com o valor do ativo total existente no sistema bancário. O descasamento pode gerar desconfiança sobre a conversibilidade dos ativos financeiros em ativos reais e precipitar a fuga de recursos do sistema bancário. Quando inferior a um (IRATPIB $<1)$, o PIB é compatível. O contrário evidencia excesso de ativos financeiros.

\subsection{Métodos Estatísticos}

\subsubsection{Janela do evento}

Os dados utilizados para efetuar os testes são referentes aos quatro períodos que antecedem a data de início da crise, com preferência para os trimestrais.

Em virtude da limitação da regressão logística em analisar poucas observações (países), relativamente ao número de variáveis (indicadores), houve a compactação das informações de quatro períodos em um indicador único, representativo da média, do desvio-padrão ou do coeficiente de variação dos quatro indicadores que antecedem as crises.

Os nomes dos indicadores submetidos aos testes iniciam com a letra "M", "D", ou "C", quando relativos à média, ao desvio-padrão ou ao coeficiente de variação, respectivamente.

\subsubsection{Regressão logística}

O emprego da análise de regressão logística (Logit) é justificado pela necessidade de estimar a probabilidade de ocorrência de crises bancárias sistêmicas, com base em um 
conjunto de variáveis explanatórias, definidas na forma de indicadores contábeis e de riscos, calculados com e sem a volatilidade.

A natureza categórica binária da variável dependente. de crise ou não-crise, recomenda o uso da Logit pelo benefício de mostrar os resultados em probabilidades, classificar as observações em grupos, ter interpretação similar à regressão linear, exigir poucos pressupostos estatísticos aos dados e conter alta confiabilidade (HAIR et al., 1998, p. 276).

Para tanto, a técnica calcula o logaritmo natural da "razão de chances" 4 de ocorrer ou não uma crise $\left(P\left(\right.\right.$ evento $\left.\left._{i}\right)\right)$ nas observações da amostra. O valor obtido é a variável dependente $X$ da equação linear que serve de base à estimação dos coeficientes $\beta$ pelo critério da máxima verossimilhança. A seguinte equação é empregada no cálculo:

$\operatorname{In}\left(\frac{P\left(\text { evento }_{i}\right)}{1-P\left(\text { evento }_{i}\right)}\right)=\beta_{0}+\beta_{1} X_{i}+\beta_{2} X_{i}+\ldots+\beta_{n} X_{i}$

Para eliminar a função logarítmica, os dois lados da equação tornam-se expoentes da constante matemática e $(2,71828)$, resultando na equação (HAIR et al., 1998, p. 278):

$$
\left(\frac{P\left(\text { evento }_{i}\right)}{1-P\left(\text { evento }_{i}\right)}\right)=e^{\left(\beta_{0}+\beta_{i} X_{i}+\beta_{2} X_{i}+\ldots+\beta_{n} X_{j}\right)}
$$

Os coeficientes estimados são, então, multiplicados pelas variáveis independentes de cada observação e o resultado é a probabilidade de ocorrência do evento. A equação logística usada nesse cálculo, na forma simplificada, conforme Gujarati (2000, p. 559), é a seguinte:

$$
P\left(\text { evento }_{i}\right)=\frac{1}{1+e^{-\left(\beta_{0}+\beta_{1} X_{i}+\beta_{2} X_{i}+\ldots+\beta_{n} X_{j}\right)}}
$$

No estudo, a variável dependente da probabilidade de ocorrência de crise no país $i, P\left(\right.$ evento $\left._{i}\right)$, assume os valores de um (1), se há crise, e de zero (0), quando não há crise.

\subsection{3 Índices de risco sistêmico (IRS)}

Para mensurar, longitudinalmente, o nível de risco sistêmico nos países da amostra, bem como facilitar a interpretação, construíram-se três índices de risco sistêmico (IRS), sendo denominados IRS-M, IRS-D e IRS-C, correspondentes às equações $13,14 \mathrm{e} 15$, expostas a seguir.

A construção dos IRS considerou o percentual de acerto ao acaso, de $53,125 \%$ (17/32), que seria obtido caso todas as observações fossem classificadas a esmo no grupo preponderante (não-suscetível à crise). O valor localizado no percentil 53,125 dos resultados da aplicação das equações 13,14 e 15 é, então, assumido como o ponto limítrofe dos grupos não-suscetível e suscetível à crise, porque induz a separação de dezessete e quinze países (53,125\% e $46,825 \%$ das observações) em cada um deles, conforme definido inicialmente.

O cálculo é feito pela substituição dos valores dos indicadores de cada país nas equações. A relação direta entre os IRS e o nível de risco sistêmico no setor bancário leva à interpretação dos IRS positivos (IRS $>0$ ) como indicativos de maior suscetibilidade à crise e, conseqüentemente, dos IRS negativos (IRS $<0)$ como sinais de menor risco.

Para avaliar o desempenho das equações, os resultados são analisados à luz da realidade, mediante a comparação das sinalizações do nível de risco sistêmico pelos IRS com as experiências reais observadas em cada país. As coincidências entre as crises e as tendências evidenciam a eficácia dos IRS em mensurar o risco sistêmico.

\section{ANÁLISE DOS RESULTADOS ESTATÍSTICOS}

Os resultados da análise de regressão logística, após sucessivos testes com os trinta indicadores, estão expostos na Tabela 10 e demonstram que apenas os indicadores correspondentes às médias da rentabilidade e do risco de crédito (MROE e MIRCRE), e aos desvios-padrão da rentabilidade, da taxa de juros e da inadimplência (DROE, DIRTJ e DCAOC) apresentam significância estatística, ao nível de 5\%.

Tabela 1 Teste de significância individual dos indicadores - Teste de Wald

\begin{tabular}{l|c|c|c|c|c|c|c|c} 
Indicador & MORE & MIRCRE & Const1* & DROE** & DIRTJ & Const2* & DCAOC & Const3* \\
\hline B & $-0,032$ & 0,042 & $-2,147$ & 0,046 & 0,001 & $-3,871$ & 1,892 & $-8,28$ \\
\hline Wald & 5,257 & 5,318 & 2,179 & 3,617 & 6,217 & 9,043 & 4,29 & 4,11 \\
\hline Sig & 0,022 & 0,021 & 0,140 & 0,057 & 0,013 & 0,003 & 0,04 & 0,04
\end{tabular}

* As constantes são das equações 13, 14 e 15. ** O nível de significância (Sig) do indicador DROE é 5,7\%. Fonte: Próprio autor com base na saída do SPSS v.10.0 
Com base nos indicadores de maior significância estatística, as equações logísticas que melhor mensuram o nível de risco sistêmico são as seguintes:

Equação 13:

$$
P\left(\text { crise }_{i}\right)=\frac{1}{1+e^{-\left(-2,147-0,032 * M R O E_{i}+0,042 * M I R C R E_{i}\right)}}
$$

Equação 14

$$
P\left(\text { crise }_{i}\right)=\frac{1}{1+e^{-\left(-3,871+0,046 * D R O E_{i}+0,001 * D I R T J_{i}\right)}}
$$

Equação 15:

$$
P\left(\text { crise }_{i}\right)=\frac{1}{1+e^{-\left(-8,279+1,892 * D C A O C_{i}\right)}}
$$

$\mathrm{Na}$ Tabela $2 \mathbf{0}$, encontram-se as equações compostas por esses indicadores (MROE e MIRCRE, DROE e DIRTJ, e DCAOC) que apresentam melhor significância estatística e maior percentual de acerto na classificação dos países quanto ao risco sistêmico.

\section{APLICAC̣ÃO DAS EQUAC̣ÕES}

A submissão dos valores calculados para os indicadores de cada país às equações com melhor significância estatística e maior percentual de acerto na classificação resulta os IRS.

Para a equação 13, que utiliza os indicadores MROE e MIRCRE, os valores resultantes estão contidos no intervalo $[0,10431 ; 0,10869]$, e o ponto de corte é 0,10478 , encontrado na posição do percentil 53,125 desses valores. Sob o mesmo raciocínio, para a equação 14 , dos indicadores DROE e DIRT], os valores estão no intervalo [0,02042; $0,02100]$ e o ponto de corte é 0,02048 . Para a equação 15 , formada unicamente pelo indicador DCAOC, os valores estão entre $[0,000254 ; 0,000290]$ e o ponto de corte é 0,000256 .

O IRS é obtido pela diferença entre o valor do ponto de corte das equações 13, 14 e 15, definidos como 0,10478;
0,02048 e 0,000256, respectivamente, e o resultado calculado em cada período pela aplicação da equação correspondente.

Para melhor compreensão, a Tabela 30 expõe o cálculo dos IRS da Islândia, com base nos valores obtidos pela aplicação das equações e deduzidos dos respectivos pontos de corte.

Os IRS da Islândia, com valores superiores a zero, indicam alto risco sistêmico no período até dezembro de 1997. Após, os IRS declinam para valores inferiores a zero, mostrando redução no risco. A exceção é o IRS-D que volta a indicar aumento no risco sistêmico após dezembro de 2000. A visualização do comportamento pode ser observada no Gráfico 5 ๑.

Tabela 2 || Resumo dos testes de validação dos modelos

\begin{tabular}{l|c|c|c|c|c}
\multicolumn{1}{c|}{ Teste } & $\mathbf{- 2 L L}$ & H\&L & Cox\&Snell & Nagelkerke & Acerto \\
Medida & \multicolumn{2}{|c|}{ Qui-quadrado } & \multicolumn{2}{|c}{$\mathrm{R}^{2}$} & $\%$ \\
\hline MROE-MIRCRE & 14,465 & 5,113 & 0,606 & 0,809 & 90,6 \\
\hline DROE-DIRTJ & 17,374 & 4,345 & 0,568 & 0,758 & 90,6 \\
\hline DCAOC & 6,374 & 0,397 & 0,694 & 0,926 & 93,8
\end{tabular}

\begin{tabular}{|c|c|c|c|c|c|c|c|c|c|c|c|}
\hline \multirow[t]{2}{*}{ Período } & \multicolumn{2}{|c|}{ Indicadores } & Eq. 13 & \multirow{2}{*}{$\begin{array}{c}\text { IRS-M } \\
0,10478 \\
\end{array}$} & \multicolumn{2}{|c|}{ Indicadores } & \multirow[t]{2}{*}{ Eq. 14} & \multirow{2}{*}{$\begin{array}{c}\text { IRS-D } \\
0,02048\end{array}$} & \multirow{2}{*}{$\begin{array}{l}\text { Indicad } \\
D C A O C\end{array}$} & \multirow[t]{2}{*}{ Eq. 15} & \multirow{2}{*}{$\begin{array}{l}\text { IRS-C } \\
0,0003\end{array}$} \\
\hline & MROE & & CRE & & DROE & DIRTJ & & & & & \\
\hline Dez-93 & $-0,022$ & 0,226 & 0,1056 & 7,9008 & 0,087 & 2,137 & 0,0205 & 0,5621 & 0,0097 & 0,00026 & 2,5577 \\
\hline Dez-94 & $-0,028$ & 0,210 & 0,1055 & 7,4206 & 0,081 & 1,973 & 0,0205 & 0,4800 & 0,0085 & 0,00026 & 1,9822 \\
\hline Dez-95 & $-0,019$ & 0,200 & 0,1055 & 6,7867 & 0,088 & 5,668 & 0,0206 & 1,2871 & 0,0083 & 0,00026 & 1,8751 \\
\hline Dez-96 & 0,043 & 0,190 & 0,1052 & 4,4776 & 0,034 & 7,587 & 0,0206 & 1,1740 & 0,0074 & 0,00026 & 1,4601 \\
\hline Dez-97 & 0,073 & 0,162 & 0,1050 & 2,4888 & 0,027 & 5,598 & 0,0205 & 0,7052 & 0,0053 & 0,00026 & 0,4476 \\
\hline Dez-98 & 0,091 & 0,126 & 0,1048 & 0,5378 & 0,021 & 1,077 & 0,0205 & $-0,2580$ & 0,0023 & 0,00025 & $-1,0280$ \\
\hline Dez-99 & 0,113 & 0,090 & 0,1046 & $-1,5508$ & 0,023 & 2,227 & 0,0205 & $-0,0085$ & 0,0016 & 0,00025 & $-1,3542$ \\
\hline Dez-00 & 0,115 & 0,053 & 0,1045 & $-3,0728$ & 0,021 & 5,665 & 0,0205 & 0,6607 & 0,0003 & 0,00025 & $-1,9688$ \\
\hline Dez-01 & 0,112 & 0,030 & 0,1044 & $-3,8847$ & 0,022 & 5,242 & 0,0205 & 0,5886 & 0,0010 & 0,00025 & $-1,6444$ \\
\hline
\end{tabular}

Fonte: Próprio autor com base na saída do SPSS v.10.0

Tabela 3 IRS da Islândia - dez/1993 a dez/2001 


\section{DEMONSTRAÇÃO GRÁFICA DO NÍVEL DE RISCO SISTÊMICO}

Os Gráficos de 1 a 6 apresentam o comportamento dos IRS em alguns países.

O Gráfico 10 exibe a evolução dos IRS no Brasil. Dois patamares distintos de risco sistêmico são observados. Até dezembro de 2000, quando os IRS apresentam valores superiores a zero e significativa volatilidade, há evidências de maior suscetibilidade à crise. Esse período abrange os dois momentos em que o Brasil esteve na iminência da crise bancária, em 1995 e 1999. Após dezembro de 2000, quando os IRS apresentam valores inferiores a zero, tendências decrescentes e volatilidades reduzidas, há redução no risco sistêmico.

O Gráfico 2 expõe a evolução dos IRS da Argentina e exibe as duas crises ocorridas no período. Enquanto na data de março de 1995 salienta-se o IRS-C, formado pelo indicador DCAOC, na crise de dezembro de 2001 todos os IRS apresentam crescimento.

A crise experimentada pela Rússia é identificada pelos três IRS apresentados no Gráfico 3 o. O IRS-C, composto pelo desvio dos créditos anormais, sinaliza o aumento do risco sistêmico a partir de setembro de 1997, um ano antes da crise. Da mesma forma, os ou- tros dois IRS também acusam aumento do risco a partir de março de 1998.

O Gráfico 40 expõe a evolução do risco sistêmico na Tailândia. A análise permite concluir que não houve o reconhecimento tempestivo dos créditos anormais no período que antecedeu a crise de setembro de 1997. Por isso, os IRS formados pelos indicadores representativos da qualidade do crédito não apresentam alterações que sinalizem o maior risco sistêmico.

A comprovação está no reconhecimento dos créditos anormais logo após a eclosão da crise. Somente o IRS calculado com base nos indicadores representativos dos desvios-padrão da rentabilidade e da taxa de juros (DROE e DIRTJ) sinalizou o aumento do risco sistêmico antes da crise, permanecendo elevado até setembro de 1999.

Após os problemas ocorridos no sistema de poupança e empréstimo americano, ao final dos anos de 1980, o sistema bancário americano demonstra baixo risco sistêmico. Os IRS menores que zero a partir de 1993, visualizados no Gráfico 60 , indicam que o volume de créditos anormais é irrelevante, assim como não há variabilidade significativa nas taxas de juros e nos resultados.

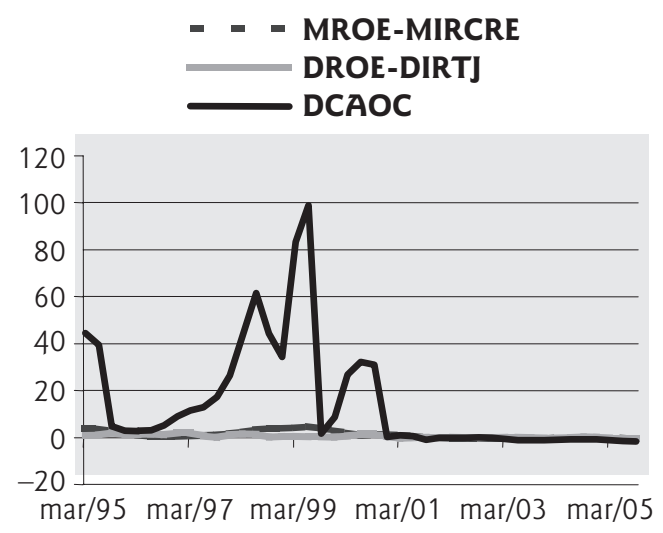

Gráfico 1 Brasil - mar/95 a jun/05

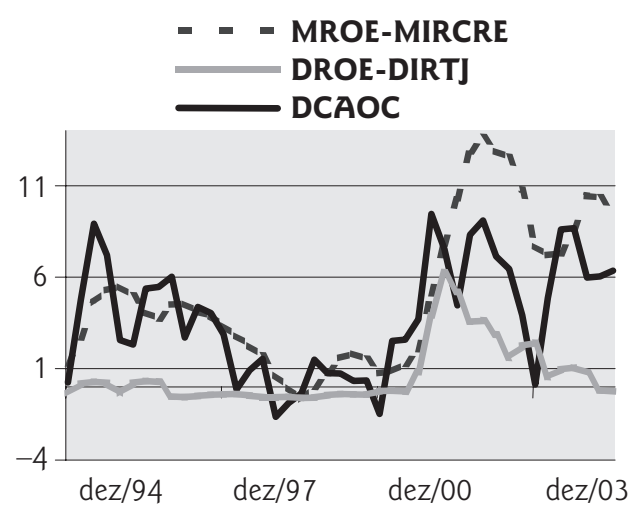

Gráfico 2 Argentina - mar/95 a jun/05
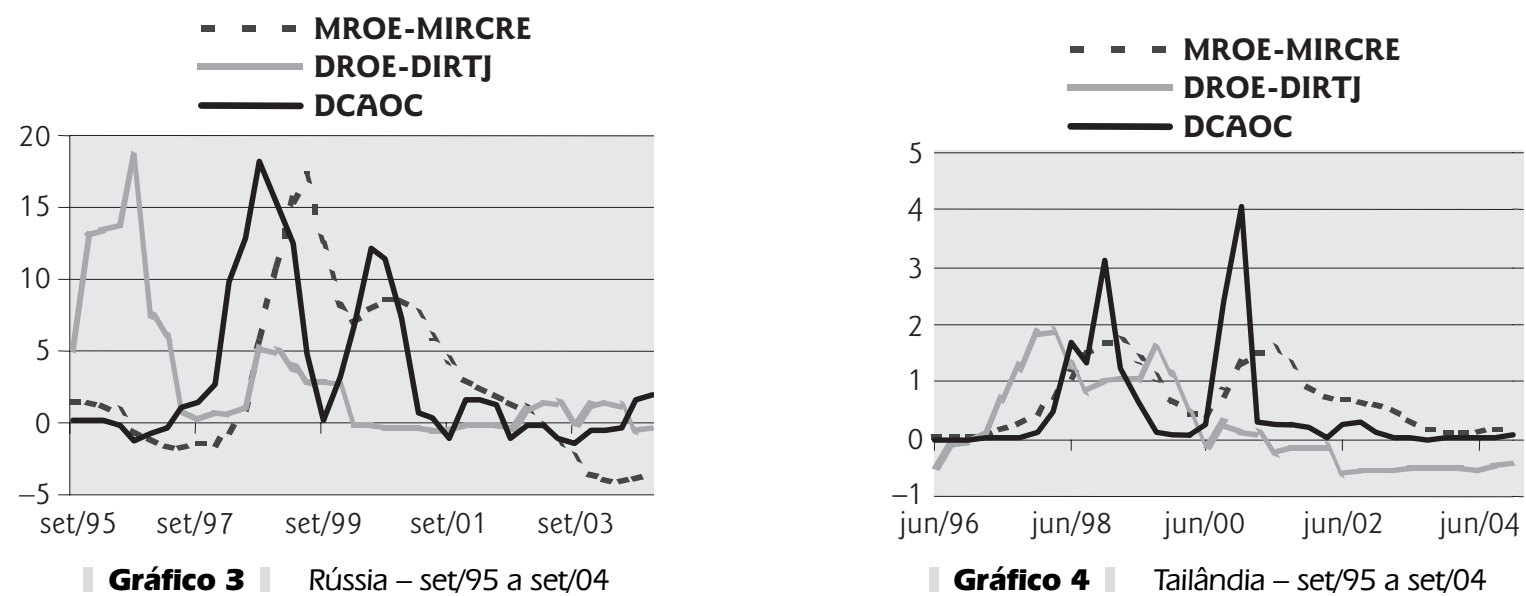

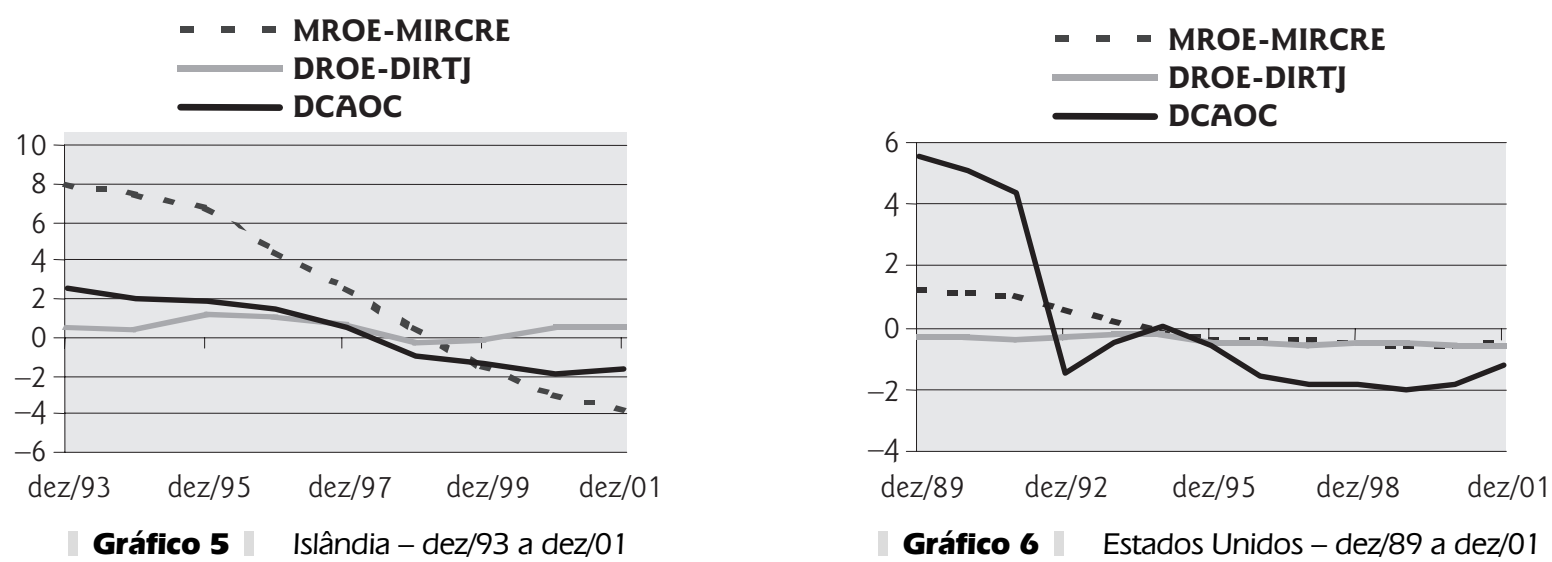

Gráfico 5 Islândia - dez/93 a dez/01

Gráfico 6 Estados Unidos - dez/89 a dez/01

\section{CONCLUSÃO}

Os testes estatísticos realizados com a regressão logística comprovaram a existência de indicadores contábeis e de riscos capazes de discriminar os sistemas bancários pelo nível de risco sistêmico. A fidelidade do comportamento dos IRS com as situações de instabilidade e estabilidade observadas no sistema bancário demonstra a eficácia dos índices.

O acompanhamento dos IRS de um país, no tempo, expõe as tendências e os pontos críticos longitudinalmente, os quais permitem análises e alterações no rumo das políticas que visem ajustar o desenvolvimento do sistema bancário à estratégia econômica implantada.

A significativa contribuição dos IRS não é prever crises, mas sim informar o nível de risco sistêmico, a fim de que medidas tempestivas, específicas e delimitadas sobre as variáveis causadoras possam ser adotadas para reduzí-lo.

Os resultados satisfatórios são explicados pela diversidade e qualidade das informações contidas nos indicadores testados, pela robustez e adequação da técnica estatística usada e, principalmente, pela existência de características comuns nos momentos que antecedem as crises, mas diferenciadas em situações normais.

As variáveis contábeis e econômicas mais associadas à ocorrência de crises estão relacionadas com a qualidade dos créditos, o volume de resultados e o nível de taxa de juros, destacando-se os indicadores que expressem as volatilidades da inadimplência, da rentabilidade e da taxa de juros, e as médias da rentabilidade e do risco de crédito.

Não obstante os resultados apresentados, a conclusão instiga à realização de novas pesquisas sobre o risco sistêmico, oferecendo um amplo espectro de oportunidades na área contábil para o entendimento desse complexo fenômeno.
A título de sugestão, a conjugação de variáveis contábeis com valores de riscos obtidos das variáveis econômicas, bem como a inserção da volatilidade no cálculo dos indicadores, parece ser um novo caminho de pesquisa. Indicadores contábeis, formados sob esse conceito, poderiam ser igualmente testados com outras informações consideradas relevantes, tais como as provenientes do mercado de capitais, a fim de identificar o grau de associação.

Quanto às causas do risco sistêmico, as abordagens são ilimitadas. Estudos empíricos para verificar como ocorre a propagação das crises, identificando as variáveis determinantes do "efeito-contágio", assim como a participação do sistema de pagamentos nesse processo, representam desafios a serem transpostos para melhorar a compreensão e o domínio do risco.

Em relação à continuidade deste estudo, a obtenção de dados individuais das instituições financeiras, de países suscetíveis ou não a crises, possibilita a realização de análises que considerem as correlações nas posições individuais, assim como o grau de concentração no sistema. A verificação da correlação e da concentração existente pode desvendar aspectos ainda não compreendidos na mensuração do risco sistêmico.

Finalmente, a divulgação das exposições líquidas em taxas de juros e de câmbio, bem como dos detalhes sobre a composição da liquidez e da mitigação da estrutura de crédito, tanto no balanço patrimonial como nas notas explicativas, revelou-se imprescindível ao desenvolvimento de instrumentos de mensuração que visem à garantia da estabilidade e à continuidade dos sistemas financeiros. 


\section{Referências}

ASSAF NETO, A. Estrutura e análise de balanços: um enfoque econômico-financeiro. 5. ed. São Paulo: Atlas, 2000.

BANK FOR INTERNATIONAL SETTLEMENTS. $64^{\text {th }}$ Annual Report. Basel: BIS, 1994.

BARTHOLOMEW, P.; WHALEN G. Fundamentals of systemic risk. Research in Financial Services: Banking, Financial Markets, and Systemic Risk. Greenwich: JAI Press, v. 7, p.3-18, 1995.

BASEL COMMITTEE ON BANKING SUPERVISION - BCBS. International convergence of capital measurement and capital standards. Basel: BCBS, 1988.

_. Amendment to the capital accord to incorporate market risks. Basel: BCBS Committee, 1996.

Sound practices for managing liquidity in banking organisations. Basel: BCBS Committee, 2000.

Principles for the management and supervision of interest rate risk. Basel: BCBS, 2004.

BERNSTEIN, P. L. Desafio dos deuses: a fascinante história do risco. Tradução de Ivo Korytowski. Rio de Janeiro: Campus, 1997.

BESSIS, J. Risk management in banking. New York: John Wiley \& Sons, 1998.

CAOUĖTTE, J. B.; ALTMAN, E. I.; NARAYANAN, P. Gestão do risco de crédito: o próximo grande desafio financeiro. Rio de Janeiro: Qualitymark, 1999.

CAPRIO Jr. et al. Preventing bank crises: lessons from recent global bank failures. Washington, DC: Economic Development Institute (EDI) - World Bank, 1998.

; KLINGEBIEL, D. Episodes of systemic and borderline financial crises. Washington: World Bank, 2003.

CROUHY, M.; GALAI, D.; MARK, R. Gerenciamento de risco: abordagem conceitual e prática. Tradução de Carlos Henrique Trieschmann e Luiz Frazã̃o Filho e supervisão de João Carlos Douat. Rio de Janeiro: Qualitymark. São Paulo: SERASA, 2004.

CREDIT SUISSE FIRST BOSTON (CSFB). CreditRisk+: a credit risk management framework: Credit Suisse Financial Products, 1997.

DEMIRGÜÇ-KUNT, A.; DETRAGIACHE, E. Cross-country empirical studies of systemic bank distress: a survey. Working Paper. Washington: IMF, WP 05/96, 2005.

DOWNING, D.; CLARK, J. Estatística aplicada. Tradução de Alfredo Alves de Farias. São Paulo: Saraiva, 1998.

FREIXAS, X.; PARIGI, B.; ROCHET, J. Systemic risk, interbank relations and liquidity provisions by the central bank. Journal of Money, Credit, and Banking, v. 32, n. 3, p. 1-37, 1999.

GOLDSTEIN, M.; KAMINSKY, G.; REINHART C. Assessing financial vulnerability: an early warning system for emerging markets. Washington, DC: IIE, 2000.

GREUNING, H. van; BRATANOVIC, S. B. Analyzing banking risk: a framework for assessing corporate governance and financial risk management. Washington, DC: World Bank, 1999.

GUJARATI, D. N. Econometria básica. 3. ed. São Paulo: Makron Books, 2000.

HAIR Jr., J. et al. Multivariate data analysis. 5. ed. New Jersey: Prentice Hall, 1998.

HONOHAN, P.; KLINGEBIEL, D. Controlling fiscal costs of banking crises. Discussion Paper. Washington, DC: World Bank, WDP428, p. $15-29,2002$.

INTERNATIONAL MONETARY FUND - IMF. Guide to the data dissemination standards: the special data dissemination standard. Washington DC: IMF, 1996.

World economic outlook. Washington DC: IMF, 1998.

Macroprudential analysis: selected aspects. Monetary and Exchange Affairs Department. Washington, DC: IMF, 2001.

JORION, P. Value at risk: a nova fonte de referência para a gestão do risco financeiro. 2. ed. São Paulo: Bolsa de Mercadorias e Futuros, 2003. KAMINSKY, G.; LIZONDO, S.; REINHART, C. M. Leading indicators of currency crises. Staff Paper. Washington, DC: IMF, v. 45, n. 1, 1998.

KEALHOFER, S.; BONH, J. R. Portfolio management default risk. San Francisco: KMV LLC, 2001.

LINDGREN, C.; GARCIA, G.; SAAL, M. I. Bank soundness and macroeconomic policy. Washington, D́C: IMF, 1996

MARKOWITZ, H. Portfolio selection. Journal of Finance, v. 7, n. 1, março 1952.

MARTINS, G. A. Manual para elaboração de monografias e dissertações. 3. ed. Sạ̃o Paulo: Atlas, 2002.

MARTINS, E.; ASSAF NETO, A. Administração financeira: as finanças das empresas sob condições inflacionárias. São Paulo: Atlas, 1986.

MATARAZZO, D. C. Análise financeira de balanços: abordagem básica e gerencial. 6. ed. São Paulo: Atlas, 2003.

MORGAN, J. P. CreditMetrics. Technical document, New York: J. P. Morgan \& Co. Incorporated, 1997.

ROSS, S. A.; WESTERFIELD, R. W.; JAFFE, J. F. Administração financeira: corporate finance. Tradução de Antonio Z. Sanvicente. São Paulo: Atlas, 1995.

SECURATO, J. R. Decisões financeiras em condições de risco. São Paulo: Atlas, 1996

; FAMÁ, R. Um procedimento para decisão de crédito pelos bancos. Revista de Administração Contemporânea - RAC, São Paulo, v. 01 , n. $1,1997$. 
SPSS Inc. SPSS regression models 12.0. In: Manual SPSS 12.0. EUA: SPSS Inc., 2003. Disponível em: <http://www.sc.uevora.pt/pdf/manual_ spss_12>. Acesso em: 11 out. 2005.

WILSON, T. C. Measuring and managing credit portfolio risk: part I - modelling systemic default risk. Risk Magazine, n. 10, sep. 1997a. Measuring and managing credit portfolio risk: part II - portfolio loss distribuitions. Risk Magazine, n. 10, oct. $1997 \mathrm{~b}$.

\section{NOTA - Endereço dos autores}

Universidade de Brasília

Faculdade de Administração, Economia, Contabilidade e Ciências da Informação e Documentação

Departamento de Ciências Contábeis e Atuariais Compus Universitário Darcy Ribeiro - Asa Norte Brasília - DF

7.0910-900
Universidade de São Paulo

Faculdade de Economia, Administração e Contabilidade

Departamento de Contabilidade e Atuária

Av. Prof. Luciano Gualberto, 908 - prédio 3 - Cidade Universitária

São Paulo - SP

05508-900. 